\title{
Life prediction of SAE 1045 carbon steel using the acoustic emission parameter
}

\begin{abstract}
The competency of acoustic emission (AE) technique in order to predict the fatigue life of SAE 1045 carbon steel was discussed in this paper. The correlation of the AE parameter and the number of cycles to failure of the tested specimens were established via the statistical approach. In this paper, The AE hits were selected as the functional parameter. The fatigue life values were calculated using the strain-life approach of three models; Coffin-Manson, Smith-Watson Topper and Morrow. Both AE and strain signals used in the analysis were captured using the $\mathrm{AE}$ sensor and strain gauge that were attached to the specimen during the fatigue test. The results show that the AE technique has a good potential in assessing the fatigue life with the designed $\mathrm{H}-\mathrm{N}$ curve (AE hits-number of cycles to failure curve).
\end{abstract}

Keyword: Acoustic emission; Fatigue life; Hits; Prediction; Steel 